\title{
Operant control of vocal responding in rats'
}

HARBAHS LAL

UNIVERSITY OF KANSAS

Using free operant as well as discriminated avoidance schedules rats were trained to vocalize in order to avoid tail shocks. Vocalization could be brought under the operant control in most of the rats.

Operant conditioning recently has been used to analyze human vocal behavior (Holz \& Azrin, 1966). The present study was an attempt to determine if vocalization in the rat can be brought under stimulus control through operant conditioning. Operant vocalization has previously been demonstrated in the parakeet (Ginsberg, 1960), the crow (Kranser, 1958), the dog (Konorski, 1948) and the chicken (Lane, 1960). Rats, however, failed to vocalize to avoid shock in experiments reported by Mowrer, Palmer, \& Sanger (1948).

The experiment reported here showed that vocalization which is generally elicited in part by electric shock can be brought under the control of a reinforcing consequence as well as of stimuli discriminative for a. reinforcing consequence.

Method

Male and female Sprague-Dawley rats of Holtzman strain served as experimental Ss. The rats were given water and food ad lib except during the trial sessions. The $S$ was held in a rat holder ${ }^{2}$ in front of a microphone in a sound insulated chamber. ${ }^{3}$ Two electrodes were taped on the tail. A Grason-Stadler shocker 4 and vocal operant relay 5 were used. 6

Two experiments were conducted. The first used a free operant avoidance situation in which every vocalization reset a recycling timer to 5 sec. Absence of vocalization for $7 \mathrm{sec}$. delivered a tall shock of $0.3 \mathrm{~mA}$ intensity and $0.2 \mathrm{sec}$. duration and was repeated every 2 sec. until a vocal response was emitted. Thus the avoidance schedule was characterized by a response-shock interval of 7 sec. (RS $7^{\prime \prime}$ ) and a shock-shock interval of 2 sec. (SS 2"'). The second experiment used a discriminated avoidance schedule. Failure to respond during the $25 \mathrm{sec}$. (time-out) period turned on the house light (discriminative stimulus). Again, responding reset a recycling timer, this time for $25 \mathrm{sec}$. A response within $7 \mathrm{sec}$. turned off the house light and recycled the timer, postponing $\mathrm{S}^{D}$ for another $25 \mathrm{sec}$. Failure to respond during the first 7 sec. of the discriminative stimulus period was followed by tail shock which was repeated every 2 sec. until a vocal response was made.

Resulits

Figure 1 gives the cumulative record of vocalization of a rat when the electrodes were disconnected.

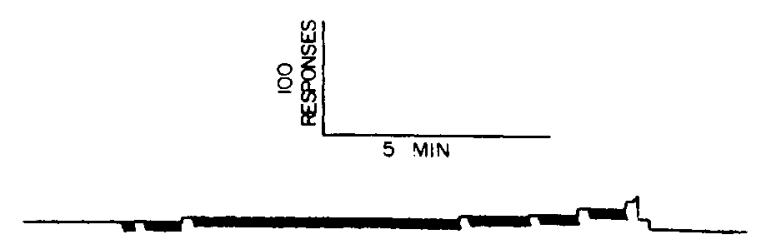

Fig. 1. Cumulative response curve for the vocal responses of the rat when shocking electrodes were disconnected. Downward deflections of the pen represent "shocks."

It is clear that the rat vocalized very little. The reinforcement blips on this record indicate the action of the recycling timer and the other equipment it controlled. It is also clear that these events did not produce spurious "responses."

Four of the 10 rats on free operant avoidance schedule acquired high rates of vocalization to avoid shock within six to 10 sessions, each session lasting for about $1 / 2 \mathrm{hr}$. daily. Figure 2 shows the cumulative rate of vocal responses for one of these rats. This $S$ showed escape response immediately, and acquired perfect avoidance behavior in six sessions. Performance of the other three rats was nearly identical. In the same period, five of the remaining six rats acquired perfect escape responses but avoided only 20-70\% of the shocks. One rat escaped all but a few shocks but did not learn to avoid at all. Vocal responses of this rat are represented in Fig. 3.

Figure 4 shows the cumulative vocalization rate for one of the four rats on the discriminated avoidance schedule. This rat avoided more than $90 \%$ of programmed shocks consistently. Two other rats

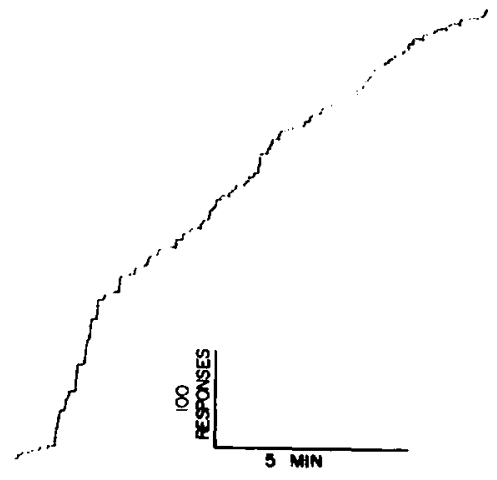

Fig. 2. Cumulative vocal responses of the rat. Downward deflections of pen represent tail shocks. 
learned to avoid nearly $50 \%$ of the programmed shocks consistently. Responses of the remaining rat either to escape or avoid shocks were not consistent from day to day.

Discussion

The experiments reported have shown that vocalization in rats can be brought under the control of operant conditioning. An aversive stimulus was used to condition the vocal responses because of the notion that rats invariably vocalize when a painful shock is applied. Use of positive reinforcers to bring the vocalization under operant control is quite conceivable. Conditioning of vocal responses for the reward of brain self-stimulation through implanted electrodes is currently being attempted in our laboratory.

Azrin (1966) stated that in animals vocalization is elicited along with aggression. Earlier, Skinner (1957) speculated that "emotional and reflex vocalizations are difficult or impossible to modify by operant reinforcement." Thus animal vocalization may be a subject of considerable importance, and demonstration of operant control may lead to a more precise analysis and interpretation of it. The present study, together with several others (Ginsberg, 1958; Lane, 1960) indicates that operant control of animal vocalization is realistic.

Vocalization in the human is undoubtedly operant in nature (Holz \& Azrin, 1966), and has been studied from the point of view of language development and speech pathology, as crying in infants (Rheingold, Gerwitz, \& Ross, 1960), and as a diagnostic tool with psychotic patients (Lindsley, 1963). Thus a general and compre-

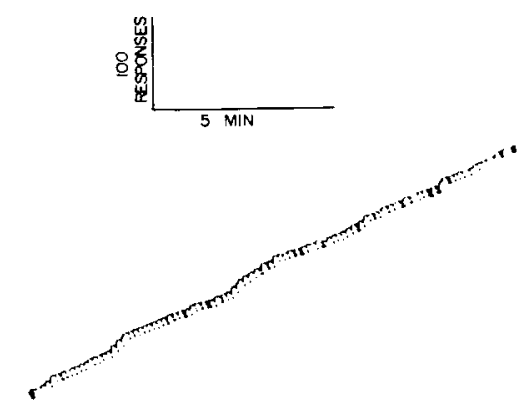

Fig. 3. Cumulative vocal responses of the rat. Downward deflections of pen represent tail shocks.

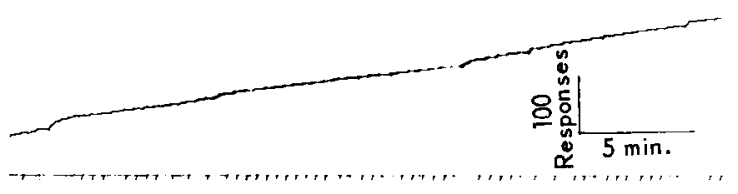

Fig. 4. Cumulative vocal responses of the rat. Event pen deflections show onset and duration of house light.

hensive analysis of vocal behavior, across all species, if possible, is potentially of great value.

\section{References}

Azrin, N. (1966) personal communication.

Ginsberg, N. Conditioned vocalization in the Budgerieger. J. comp. physiol. Psychol., 1960, 53, 183-186.

Holz, W. C., \& Azrin, N. H. In W. K. Honig (Ed.), Operant behavior. New York: Appleton-Century-Croft, 1966. Pp. 790-826.

Konorski, J. Conditioned reflexes and neurone organization. Cambridge: University Press, 1948.

Kranser, $\mathbf{L}$. Studies of the conditioning of verbal behavior. Psychol. Bull., 1958, 55, 148-170.

Lane, H. Control of vocal responding in chickens. Science, 1960, $132,37-38$.

Lindsley, $\mathbf{O}$. R. Direct measurement and functional definition of vocal hallucinatory symptoms. J. nerv. ment. Dis., 1963, 136, 293-297.

Mowrer, O. H., Palmer, F., \& Sanger, M. D. Individual learning and racial experience in the rats with special reference to vocalization. J. genet. Psychol., 1948, 73, 29-43.

Rheingold, H. L., Gerwitz, J. L., \& Ross, H. W. Social conditioning of vocalization in the infants. J. comp. physiol. Psychol., 1960. $52,68-73$.

Skinner, B. F. Verbal behavior. New York: Appleton-CenturyCrofts, 1957. Pp. 53-54.

\section{Notes}

1. The author is grateful to Professor Ogden Lindsley for valuable suggestions and Professor Donald Baer for critical review of this manuscript. Technical assistance of Richard Schaffer is appreciated. This investigation was supported by grant GE-1129 from National Science Foundation. Reprints may be obtained from Harbans Lal, Department of Pharmacology, University of Rhode Island, Kingston, Rhode Island, 02881.

2. Aloe Apparatus $\mathrm{Co}$.

3. Lehigh Valley Electronic Model 1316C.

4. Model E1064GS.

5. Model E7300A-1.

6. Before placing the rat in the testing chamber, all of the experimental sequence was run with an empty rat holder in the chamber to examine the possibility of any interference or spurious "responses" from extraneous click sounds. No such "response" was detected. 